\title{
Creation of the system of differential training to disciplines in the sphere of technical regulation
}

\author{
Bukrieieva 0.* \\ Kharkiv National Automobile and Highway University, Kharkiv, Ukraine
}

Received: $17.09 .2018 \quad$ Accepted: 20.10 .2018

\begin{abstract}
In the modern conditions of globalization, the competition between specialists in the labor market increases in many times, which intensifies the task of forming professionally significant skills of the student. One of the ways to solve it is the individualization of learning and its variety: differentiated and different levels of education. The analysis of publications showed that these pedagogical technologies are rarely used in the teaching of specialized disciplines in higher education. In this regard, the peculiarities of the application of different levels of education in the university are revealed. This allowed to develop a system of different levels of training in the field of technical regulation, the main feature of which is the student's absolute voluntariness. Preliminary level differentiation occurs at the lectures by selecting a student of additional handouts and literature, the main form of its organization is practical training. At the same time, the level differentiation was carried out according to the types of activity in accordance with the taxonomy of Bloom. To assess the activities of students, criteria have been proposed and an adaptive testing system has been created. Approbation of this development was carried out with students of 3-5 courses on the disciplines "Fundamentals of Standardization", "Fundamentals of certification", "Certification and technical expertise of construction and road machinery." It was found out that in the third year the quality and success of the teaching practically did not change. In the fourth year, the success rate increased by $10.4 \%$, and the quality - by $14.1 \%$; on the 5 th course, the success increased by $12.7 \%$, the quality - by $28 \%$. Thus, the conducted pedagogical experiment demonstrates the positive dynamics of the application of this pedagogical technology, however, its use is not advisable in junior courses in the study of profile disciplines. On the 4th course, the success rate increased by $10.4 \%$, and the quality - by $14.1 \%$, on the 5 th course the success increased by $12.7 \%$, the quality by $28 \%$. Thus, the conducted pedagogical experiment demonstrates the positive dynamics of the application of this pedagogical technology, however, its using is not advisable in junior courses in the study of profile disciplines.

Key words: standardization; certification; technical regulation; multilevel training; higher education institution.
\end{abstract}

\section{Создание системы разноуровневого обучения дисциплинам в сфере технического регулирования}

Букреева О. С.

\author{
Харьковский национальный автомобильно-дорожный университет, Харьков, Украина
}

\begin{abstract}
Аннотация. В современных условиях глобализации многократно возрастает конкуренция между специалистами на рынке труда, что интенсифицирует задачу формирования профессионально значимых навыков студента. Одним из путей ее решения является индивидуализация обучения и ее разновидности: диффференцированное и разноуровневое обучение. Анализ публикаций показал, что указанные педагогические технологий редко применяют при преподавании профильных дисциплин в высшей школе. В связи С этим выявлены особенности применения разноуровневого обучения в вузе. Это позволило разработать систему разноуровневого обучения дисциплинам в сфере технического регулирования, основной особенностью которой является абсолютная добровольность студента. Предварительная уровневая дифференциация происходит на лекциях путем выбора студентом дополнительного раздаточного материала и литературы, основная же форма его организации - практические занятия. При этом уровневая диффференциация проведена по видам деятельности в соответствии с таксономией Блума. Для оценивания деятельности студентов предложены критерии и создана система адаптивного тестирования. Апробация данной разработки была проведена со студентами 3-5 курсов по дисциплинам «Основы стандартизации»,
\end{abstract}

Corresponding Author: Bukrieieva Olha Serhiivna, Phone: +38(095)359-48-67. E-mail: olga_bukreeva@ukr.net Kharkiv National Automobile and Highway University,vul. Yaroslava Mudroho, 25, Kharkiv, Ukraine, 61002.

Відповідальний автор: Букрєєва Ольга Сергіївна, Тел. +38(095)359-48-67. E-mail: olga_bukreeva@ukr.net Харківський національний автомобільно-дорожній університет, вул. Ярослава Мудрого, 25, Харків, Україна, 61002. 
«Основы сертификации», «Сертификация и техническая экспертиза строительных и дорожных машин». Выявлено, что на третьем курсе качество и успешность обучения практически не изменились. На 4-ом курсе успешность увеличилась на 10,4\%, а качество - на 14,1\%, на 5-ом курсе успешность - на 12,7\%, качество $28 \%$. Т. о., проведенный педагогический эксперимент демонстрирует положительную динамику применения данной педагогической технологии, однако, ее использование не целесообразно на младших курсах при изучении просильных дисциплин.

Ключевые слова: стандартизация; сертификация; техническое регулирование; разноуровневое обучение; высшее учебное заведение.

\title{
Створення системи різнорівневого навчання дисциплінам у галузі технічного регулювання
}

\author{
Букрєєва О.С. \\ Харківський національний автомобільно-дорожній університет, Харків, Україна
}

\begin{abstract}
Анотація. У сучасних умовах глобалізації багаторазово зростає конкуренція між фахівцями на ринку праці, що інтенсифікує завдання формування профресійно значущих навичок студента. Одним із шляхів його вирішення $€$ індивідуалізація навчання та їі різновиди: диференційоване і різнорівневе навчання. Аналіз публікацій показав, що зазначені педагогічні технологій рідко застосовують при викладанні профільних дисциплін у вищій школі. У зв'язку з цим виявлені особливості застосування різнорівневого навчання в вузі. Це дозволило розробити систему різнорівневого навчання дисциплін у галузі технічного регулювання, основною особливістю якої $є$ абсолютна добровільність студента. Попередня рівнева диференціація відбувається на лекціях шляхом вибору студентом додаткового роздаткового матеріалу і літератури, основна ж форма його організації - практичні заняття. При цьому рівнева диференціація проведена за видами діяльності відповідно до таксономії Блума. Для оцінювання діяльності студентів запропоновано критерії і створена система адаптивного тестування. Апробація даної розробки була проведена зі студентами 3-5 курсів з дисциплін «Основи стандартизації», "Основи сертифікації», «Сертифікація та технічна експертиза будівельних і дорожніх машин». Виявлено, що на третьому курсі якість і успішність навчання практично не змінилися. На 4му курсі успішність збільшилася на 10,4\%, а якість - на 14,1\%, на 5-му курсі успішність - на 12,7\%, якість $28 \%$. Т. ч., проведений педагогічний експеримент демонструє позитивну динаміку застосування даної педагогічної технології, проте, їі використання не доцільно на молодших курсах при вивченні профільних дисциплін.
\end{abstract}

Ключові слова: стандартизація, сертифікація, технічне регулювання, різнорівневе навчання, вищий навчальний заклад.

\section{I Введение}

Современные условия рынка труда, а также реформирование системы образования в Украине создают необычайно высокий уровень конкуренции между специалистами. Эти факторы интенсифицируют задачу формирования профессионально значимых навыков студента. Достичь ее представляется возможным через создание оптимальных условий для реализации его потенциальных возможностей и стимулирования его субъективной активности, чему способствует большая индивидуализация обучения.

Средствами индивидуализации обучения могут выступать персональные и групповые задания, реализация которых осуществима, в том числе, путем диффференциации обучения на основе разделения учащихся на различные по численности группы с характерными для них признаками для подбора специфических методов и приемов работы с каждой группой [1].

Некоторые ученые (В.А. Крутецкий, Е.Я.Голант) полностью отождествляют понятия индивидуализации и дифференциации. Мы же согласны с учеными (Г. Д. Глейзер, В. А. Гусев), которые считают одно частным случаем другого. Их отличиям в обстановке вуза уделено внимание в [2]. Кроме того, авторы [3] хоть и разделяют индивидуальное и дифференцированное обучение, однако подчеркивают необходимость создания разноуровневых заданий для свободного их выбора студентом.

В условиях высшей школы, на наш взгляд, организационно целесообразнее осуществлять уровневую дифференциацию, которая предполагает разный уровень усвоения учебного материала, но не ниже базового, предписанного образовательно-профессиональной программой. При этом учащийся имеет возможность свободного выбора уровня обучения и перехода между ними [4]. Поскольку эта 
технология была целенаправленно разработана и внедрена в средней школе, то относительно ее применения в вузе остается еще значительное число нерешенных задач.

Актуальным вопросам реализации дифференцированного обучения в высшей школе посвящены исследования ученых Ю. К. Бабанского, А. И. Богомолоав, Б. Б. Коссова, В. Я. Ляудиса, М. Фишбейна и др.

Системная апробация разноуровневого обучения в течение нескольких курсов была осуществлена авторами [5], которые пришли к выводу о большей его эффективности по сравнению с традиционным обучением как по количеству, так и по качеству решенных задач, что свидетельствует о преимуществе целенаправленного отбора и конструирования учебной информации в повышении активности и успешности познавательной деятельности студентов.

На основе этого, авторами [6] разработана система разноуровнего обучения в техническом вузе, которая включает в себя изменение структуры лекции, практик, лабораторных и самостоятельных работ, а также контроля знаний с банком задач по модулям, темам и уровням сложности.

Однако, проведенный анализ публикаций выявил, что эту педагогическую технологию в вузе предпочитают реализовывать в рамках общетехнических дисциплин (высшая математика, информатика, начертательная геометрия, физика [2, 3, 6-12]) в аудиторной и самостоятельной работе. В то же время, ее не применяют при преподавании дисциплин профессионального цикла, т.к. возникает необходимость создания множества различных программ обучения, методических указаний, систем контроля с учетом специфики каждой специальности.

В связи с этим целью статьи является разработка и анализ эффективности системы разноуровневого обучения дисциплинам в сфере технического регулирования, а именно: основы стандартизации, основы сертификации, сертификация и техническая экспертиза строительных и дорожных машин (СДМ).

\section{II Материал и методы исследования}

Используя описание педагогической технологии разноуровневого обучения из $[4,13]$, можно выделить организационно-методические особенности применения ее в вузе.

В отличие от средней школы вуз - это уже заведение профильного обучения. Также, в профессиональном образовании дифференциация на основе программ разного уровня происходит в зависимости уровня аккредитации учебного заведения. Т. о., дальнейшая дифференциация в вузе может происходить внутри академических групп условно и добровольно со стороны студента без вмешательства администрации.

Кроме того, в средней школе для учащихся, не справившихся с ключевыми заданиями, организуется коррекционная работа. В то время как в вузе существует минимальный балл положительной оценки, получение которого полностью находится в поле ответственности студента, а дополнительные консультации часто проходят в индивидуальном порядке по его инициативе и договоренности с преподавателем. Также, для вуза характерна возможность обучения по индивидуальному плану для любого студента по его желанию, а не только для опережающих.

Подготовительный этап разноуровневого обучения предполагает проведение вводного контроля, что в вузе массово характерно для первокурсников по общеобразовательным дисциплинам. В дальнейшем функцию предварительного диагностирования уровня студента выполняет итоговая оценка по ранее изученной взаимосвязанной дисциплине. Коррекция выявленных пробелов и неточностей также большей частью является прерогативой студента, зависящей от степени его мотивации. Повторное объяснение с использованием дополнительных дидактических средств может происходить индивидуально на практических и семинарских занятиях.

Оценивание сверхнормативной части работы может осуществляться: преподавателем практики, лектором, педагогом-консультантом, самостоятельно, другим студентом, частно или публично, тестированием, эссе, проектом и др., а также комбинацией этих методов.

В довершение этого, поскольку число аудиторных часов в вузе нормативно и рассчитано на базовый уровень, то выполнение усложненных заданий требует существенной предварительной подготовки студента за счет самостоятельной работы, в зависимости от его потребности. 
Выявленные особенности позволяют разработать систему разноуровневого обучения дисциплинам в сфере технического регулирования, первым этапом которого является определение уровней обучения студентов.

Педагоги высшей школы предлагают проводить уровневую дифференциацию по различным признакам с количеством уровней от 2 до 4 :

1) по усложнению содержания задач и изменению вида их представления [7];

2) на основе индивидуального профиля способностей студента [9];

3) по степени усвоения предыдущего материала [10];

4) по степени подробности методических указаний, причем сложный уровень - задания исследовательского характера [11, 12];

5) по результатам таксономического анализа обучаемых - на репродуктивные (ориентировочный, алгоритмический) и продуктивные (эвристический, креативный) уровни [5]

6) по скорости освоения учебного материала [2];

7) по степени помощи со стороны преподавателя [2].

Анализируя представленные способу уровневой дифференциации, видно, что в п. 1 изменение вида представления задачи не обязательно свидетельствует об увеличении ее сложности. Мы согласны с [7] в том, что необходимо увеличивать сложность задач, однако необходимо иметь конкретный критерий их сложности.

Пп. 2 и 3 предполагают обязательное усвоение предыдущего материала для перехода на более сложный уровень, что делает невозможным свободный переход студента между уровнями, как предусмотрено в технологии разноуровневого обучения.

Пп. 4 и 7 являются следствием уровневой диффференциации, а не его основой. П. 6 свидетельствует о психофизической основе выбора уровня студентом, а не о его методическом содержании.

Наиболее близким к условиям обучения профильным дисциплинам нам представляется способ из п. 5 с делением уровней на репродуктивный и продуктивный. Однако, этот способ также требует от студента постепенного перехода с уровня на уровень.

С учетом действующей в Украине Европейской кредитно-трансферной системы (ECTS) [14] при изучении профильных дисциплин в вузе целесообразно формировать уровни обучения по увеличению исследовательской деятельности студента в соответствии с таксономией целей Блума [15] (табл. 1). При этом специфика дисциплин в сфере технического регулирования такова, что студенту достаточного базового уровня по любой теме, чтобы перейти на более сложный в последующих.

Табл. 1. Уровневая дифференциация при изучении профильных дисциплин в вузе

\begin{tabular}{|c|l|l|c|}
\hline \multicolumn{1}{|c|}{ Уровень } & \multicolumn{1}{c|}{ С (базовый) } & В (средний) & А (сложный) \\
\hline Деятельность по Блуму [15] & $\begin{array}{l}\text { вспоминание } \\
\text { осознание }\end{array}$ & применение, анализ & оценка, создание \\
\hline
\end{tabular}

Как выделено в [6], система разноуровневого обучения одной дисциплине в вузе предполагает методическое реформирование всех его составляющих.

Т. о., в связи с малым количеством аудиторных часов (50\% для бакалавров [14]) изменить структуру и тематику лекций по дисциплинам в сфере технического регулирования не представляется допустимым. Однако заложить основу для уровневой дифференциации возможно путем предоставления дополнительного раздаточного материала с литературными ссылками, который студенты могут взять по желанию. При этом базовый раздаточный материал будет содержать слайды презентации к лекции, дополнительный - схемы, таблицы, графики, рисунки выдержки из вспомогательной литературы, инфрормационных ресурсов, научных статей, патентов, нормативных и правовых документов и др.

Максимальную степень уровневой дифференциации внутри одной дисциплины мы считаем возможным реализовать на практических занятиях, примеры которых приведены в таблице 2. При этом работа может быть организована индивидуально, в парах или группах по желанию студента. 
Самостоятельная разноуровневая работа может быть организована по аналогии с практическими занятиями. Однако, мы считаем, что студенту необходимо предоставить максимальную свободу выбора, чтобы он мог сам решить, какую тему (согласно рабочей программе) и как подробно ему изучать, чтобы достичь желаемого уровня.

Табл. 2. Задания для практических занятий

\begin{tabular}{|c|c|c|c|}
\hline \multirow{2}{*}{$\begin{array}{c}\text { Темы практических } \\
\text { работ }\end{array}$} & \multicolumn{3}{|c|}{ Задания } \\
\hline & Уровень С (базовый) & Уровень В (средний) & Уровень А (сложный) \\
\hline $\begin{array}{l}\text { Изучение работы } \\
\text { национальных } \\
\text { органов } \\
\text { стандартизации } \\
\text { европейских стран }\end{array}$ & $\begin{array}{l}\text { Изучить работу } \\
\text { национальных органов } \\
\text { стандартизации } \\
\text { зарубежных стран по } \\
\text { учебнику, ответить на } \\
\text { вопросы по работе } \\
\text { одного из них }\end{array}$ & $\begin{array}{l}\text { Изучить работу } \\
\text { национального органа } \\
\text { стандартизации одной } \\
\text { из зарубежных стран } \\
\text { по свободным } \\
\text { источникам, } \\
\text { подготовить краткий } \\
\text { доклад }\end{array}$ & $\begin{array}{l}\text { В + провести } \\
\text { сравнительный анализ } \\
\text { работы представленных } \\
\text { национальных органов } \\
\text { стандартизации, } \\
\text { предложить изменения в } \\
\text { работе национального } \\
\text { органа на основе } \\
\text { зарубежного опыта }\end{array}$ \\
\hline $\begin{array}{l}\text { Написание } \\
\text { пояснительной } \\
\text { записки к проекту } \\
\text { национального } \\
\text { стандарта }\end{array}$ & $\begin{array}{l}\text { Написать } \\
\text { пояснительную записку } \\
\text { к действующему } \\
\text { национальному } \\
\text { стандарту по образцу }\end{array}$ & $\begin{array}{l}\text { Определить } \\
\text { требования к } \\
\text { содержанию } \\
\text { пояснительной записки } \\
\text { и составить ее к } \\
\text { действующему } \\
\text { национальному } \\
\text { стандарту }\end{array}$ & $\begin{array}{l}\text { Подготовить проект } \\
\text { национального стандарта } \\
\text {, оформить его в } \\
\text { соответствии с } \\
\text { требованиями, написать к } \\
\text { нему техническое } \\
\text { задание и пояснительную } \\
\text { записку }\end{array}$ \\
\hline $\begin{array}{l}\text { Подготовка } \\
\text { документов по } \\
\text { сертификации } \\
\text { продукции }\end{array}$ & $\begin{array}{l}\text { Изучить содержание } \\
\text { готовых документов по } \\
\text { сертификации } \\
\text { продукции, ответить на } \\
\text { вопросы }\end{array}$ & $\begin{array}{l}\text { Определить перечень } \\
\text { документов и их форму } \\
\text { + A }\end{array}$ & $\begin{array}{l}\text { деловая игра + метод } \\
\text { проектов [16] }\end{array}$ \\
\hline
\end{tabular}

Для оценивания работы студентов ECTS предлагает оперировать такими характеристиками, как «ошибка», «значительная ошибка», «посредственно», «выше среднего», «минимальные критерии оценивания», «недостаток» и др. В то же время, содержание этих критериев должны определить вузы самостоятельно [14].

В связи с этим необходимо определить критерии оценивания деятельности студентов на каждом уровне в системе разноуровневого обучения дисциплинам в сфере технического регулирования. Для этого используем перечень знаний и умений, которые получит студент после изучения дисциплины, указанные в учебной программе, а также виды деятельности по Блуму [15]. С учетом минимального балла для получения положительной оценки в Харьковском национальном автомобильно-дорожном университете (ХНАДУ) равного 60, получим критерии оценивания в таблице 3.

Табл. 3. Критерии оценивания

\begin{tabular}{|l|l|l|}
\hline Уровень & Балл & Критерии \\
\hline C & $60-74$ & Знать основные понятия, явления, процессы \\
\hline B & $75-89$ & $\begin{array}{l}\text { Уметь рассчитывать, выбирать, обосновывать, определять порядок действий, } \\
\text { осуществлять действия по образцу или под руководством }\end{array}$ \\
\hline A & $90-100$ & $\begin{array}{l}\text { Организовывать деятельность, анализировать и совершенствовать процессы, } \\
\text { осуществлять действия в реальных условиях с реальными объектами }\end{array}$ \\
\hline
\end{tabular}


В то же время, полученный балл не всегда может соответствовать выбранному уровню задания, который, в свою очередь, не означает автоматически оценку выше определенного балла. Первичным являются выполненные действия и их правильность. Вместе с тем, эта оценка не может быть выше, чем предусмотрено за этот уровень задания. При этом оценивание может проходить с участием взаимопроверок студентов, когда уровень А проверяет уровень В, а тот уровень С.

Итоговое оценивание по дисциплине разработано в виде закрытого адаптивного тестирования, в котором каждое последующее задание выбирается в зависимости от ответов на предыдущие. Банк вопросов по каждой дисциплине содержал 90 заданий различных уровней сложности, при этом 20 вопросов уровня C, 30 - уровня В и 40 - уровня А. Вопросы выбираются автоматически и произвольно по 50\% с каждого уровня.

На первом этапе студенту предлагаются вопросы с альтернативным выбором ответа на знание терминов, на втором - задания с множественным выбором необходимых объектов, элементов, условий в том или ином случае, на третьем - установить порядок действий, указать соответствие.

Переход на следующий уровень осуществляется, если студент ответил правильно на $60 \%$ предложенных вопросов данного уровня или на 3 первых вопроса на уровне C, 5 - на уровне В и 7 - на уровне А. В противном случае тестирование завершается.

Тогда, итоговая оценка за дисциплину выставляется по ECTS как сумма баллов за практические занятия и тестирование с учетом их весовых коэфффициентов:

$$
\mathrm{O}=\alpha \frac{\sum_{i=1}^{n} \mathrm{O}_{i}^{\text {пр }}}{n}+\beta \cdot \mathrm{O}^{\mathrm{T}},
$$

где $\mathrm{O}^{\text {пр }}$ - балл за практическое занятие, $n$ - их количество, $\mathrm{O}^{\mathrm{T}}$ - балл за тестирование, $\alpha$ и $\beta$ весовые коэффрициенты $\mathrm{O}^{\text {пр }}$ и $\mathrm{O}^{\mathrm{T}}$ соответственно.

Мы считаем, что для развития профессионально значимых навыков студента наибольшее значение имеют практические занятия, поэтому $\alpha=0,6, \beta=0,4$.

\section{III Результаты}

Описанная разработка была апробирована в 2017/2018 учебном году со студентами механического фракультета ХНАДУ:

- при подготовке магистров по специальности 133 «Отраслевое машиностроение» при изучении дисциплины «Сертификация и техническая экспертиза СДМ»;

- при подготовке бакалавров по специальности 152 «Метрология и информационноизмерительная техника» при изучении дисциплины «Основы сертификации» (4 курс) и «Основы стандартизации» (3 курс).

На рисунке 1 приведен пример схемы образовательных траекторий пяти студентов на практических занятиях по дисциплине «Основы стандартизации».

Сложность заданий к ним была выбрана студентами самостоятельно. При этом только 8\% студентов не полностью справились с заданием и получили оценку ниже выбранного уровня (обозначено красным маркером на рис. 1). Это свидетельствует о достаточной внутренней мотивации студентов и их объективной самооценке.

В эксперименте приняло участие 60 студентов, при этом определение эффрективности разноуровневого обучения было проведено в сравнении с предыдущими потоками указанных специальностей.

Количественные результаты обучения приведены в таблице 4. Они показывают, что на третьем курсе качество и успешность обучения практически не изменились.

На 4-ом курсе успешность увеличилась на 10,4\%, а качество - на 14,1\%, на 5-ом курсе успешность - на $12,7 \%$, качество - на $28 \%$. 


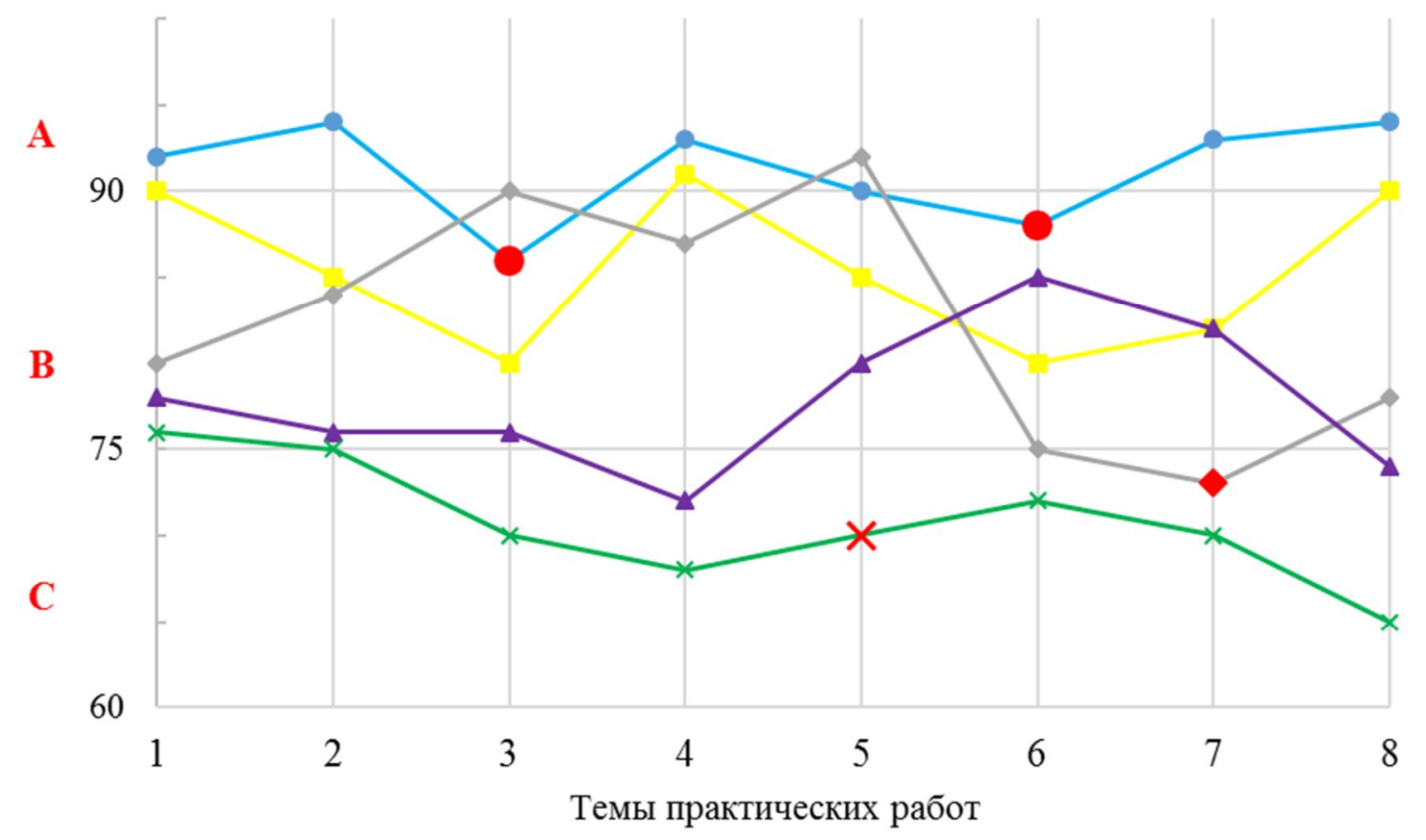

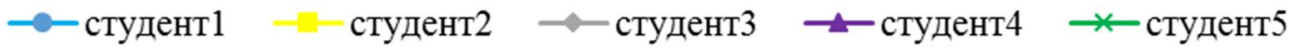

Рис. 1. Схема образовательных траекторий по дисциплине «Основы стандартизации»

Табл. 4. Количественные показатели результатов обучения

\begin{tabular}{|c|c|c|c|c|c|c|}
\hline \multirow{2}{*}{$\begin{array}{c}\text { Учебный } \\
\text { год }\end{array}$} & \multicolumn{4}{|c|}{ Итоговая оценка } & \multirow{2}{*}{$\begin{array}{c}\text { Успеш- } \\
\text { ность }\end{array}$} & \multirow{2}{*}{ Качество } \\
\hline & Неуд. (0-59) & Уд. (60-74) & Xop. (75-89) & Отл. (90-100) & & \\
\hline \multicolumn{7}{|c|}{ «Сертиффикация и техническая экспертиза СДМ» (5 курс) } \\
\hline $2016 / 2017$ & $12,70 \%$ & $30,10 \%$ & $30,80 \%$ & $26,40 \%$ & $87,30 \%$ & $57,2 \% \%$ \\
\hline 2017/2018 & 0 & $14,80 \%$ & $47,10 \%$ & $38,10 \%$ & $100 \%$ & $85,20 \%$ \\
\hline \multicolumn{7}{|c|}{ «Основы сертификации» (4 курс) } \\
\hline 2016/2017 & $10,40 \%$ & $25,80 \%$ & $34,30 \%$ & $29,50 \%$ & $89,60 \%$ & $63,80 \%$ \\
\hline 2017/2018 & $0 \%$ & $22,10 \%$ & $43,30 \%$ & $34,60 \%$ & $100 \%$ & $77,90 \%$ \\
\hline \multicolumn{7}{|c|}{ «Основы стандартизации» (3 курс) } \\
\hline 2016/2017 & $8,30 \%$ & $26,20 \%$ & $35,40 \%$ & $30,10 \%$ & $91,70 \%$ & $65,50 \%$ \\
\hline 2017/2018 & $7,90 \%$ & $27,30 \%$ & $36,20 \%$ & $28,60 \%$ & $92,10 \%$ & $64,80 \%$ \\
\hline
\end{tabular}

\section{IV Обсуждение}

Полученные данные позволяют сделать вывод, что эфффективность педагогической технологии разноуровневого обучения увеличивается на старших курсах. Мы считаем, что причиной этого является большая мотивированность студентов, объективность самооценки и нацеленность на будущую профессию. В то время как студенты третьего курса больше нуждаются в руководстве педагога и внешней мотивации.

\section{V Выводы}

Проведенный анализ выявил потребность в большей индивидуализации обучения в вузе, реализовать которую возможно путем организации разноуровневого обучения. Однако, выделенные особенности его применения в вузе свидетельствуют о необходимости разработки нового методического обеспечения: раздаточного материала, методических указаний к практическим работам для разных уровней, новой платформы тестирования. Это требует от педагога больших временных 
затрат и усилий. Также спецификой разноуровневого обучения в вузе выявлена большая значимость самостоятельной работы студента, потребность в его значительной внутренней мотивации, осознанности и интенциональности.

Разработанная система разноуровневого обучения дисциплинам в сфрере технического регулирования и ее апробация демонстрирует в целом положительную динамику его применения в высшей школе. В то же время выявлено, что данная педагогическая технология не целесообразна на младших курсах при изучении профильных дисциплин.

\section{Библиографические ссылки}

[1] Современный образовательный процесс: основные понятия и термины / Авторы-составители М. Ю. Олешков и В. М. Уваров. М. : Компания Спутник+, 2006. 191 с.

[2] Харитонова И. В. Диффреренцированный подход к организации самостоятельной работы студентов при обучении математике / Вестник Мордовского университета. 2015. Т. 25. № 1. С. 30-36

[3] Корытов И. В., Корытова Г. С. Диффреренциация и индивидуальный подход в обучении высшей математике студентов технического вуза / И. В. Корытов, // Вестник ТГПУ. 2016. № 4 (169). С. 33-41.

[4] Бухаркина М. Ю.Технология разноуровнего обучения / Иностранный язык в школе. 2003. №3. С. $48-53$.

[5] Белошицкий А. В., Душин А. В. Опыт дифференцированного обучения в техническом вузе / Педагогика. 2004 . № 7. C. $51-54$.

[6] Глушкова Л. М. Реализация индивидуального подхода при разноуровневом проблемно-модульном обучении математике в технических вузах / Вестник Башкирского университета. 2007. Т. 12. №4. С. 211-215.

[7] Шаров С. В. Використання диференційованих навчальних завдань під час самостійної роботи студентів / Проблеми фізичного виховання і спорту. 2011. № 3. С. 151-153.

[8] Ильинская Л. Н. Об организации самостоятельной работы студентов педагогических вузов по курсу «математический анализ» в условиях уровневой диффреренциации обучения / Наука и школа. 2013. № 2. С. 95-98

[9] Костина Е. А. Построение дифференцированного обучения высшей математике в техническом вузе с учетом индивидуального профиля математических способностей студента / Омский научный вестник. 2007. № 3 (60). С. 118122.

[10] Мухіна О. В., Бабєнко В. М. Про диференційоване навчання дисципліні «Нрисна геометрія і інженерна графріка» / Науковий вісник НЛТУ України. 2009. Вип. 19.11. С. 320-325.

[11] Павлуцкая Н. М. Разноуровневые лабораторные работы как средство формирования общекультурных компетенций при обучении физике бакалавров технических направлений подготовки / Ученые записки. Теория и методика обучения физике. 2014. № 6(59). С. 135-138.

[12] Китаевская Т. Ю., Авдеева Н. А. Система форм организации дифференцированного обучения информатике в вузе / Вестник ТГУ. 2008. Т.13. Вып.1. С. 91-93.

[13] Вайндорф-Сысоева, М. Е., Крившенко Л. П. Педагогика : учебное пособие для СПО и прикладного бакалавриата. М. : Издательство Юрайт, 2014. 197 с.

[14] Лист Міністерства освіти і науки України «Про методичні рекомендації щодо запровадження Європейської кредитнотрансферної системи та їі ключових документів у вищих навчальних закладах» № 1/9-119 від 26.02.2010 р. (Нормативний документ Міністерства освіти і науки України)URL: [https://ru.osvita.ua/legislation/Vishya_osvita/6810/] (дата звернення 03.09.2018).

[15] Биков В. Ю. Технологія створення дистанційного курсу: навчальний посібник ; за ред. В. Ю. Бикова та В. М. Кухаренка. К. : Міленіум, 2008. 324 с.

[16] Букреева О. С. Использование метода проектов и деловых игр в преподавании дисциплин в сфере оценки соответствия / Педагогіка безпеки. 2017. № 2. С. 83-91.

\section{References}

[1] Oleshkov, M. Yu., Uvarov V. M. (2006). Sovremennyy obrazovatelnyy protsess: osnovnye ponyatiya i terminy [Modern educational process: basic concepts and terms]. Moscow: Kompaniya Sputnik+. (in Russian)

[2] Haritonova, I. V. (2015). Differentsirovannyiy podhod k organizatsii samostoyatelnoy rabotyi studentov pri obuchenii matematike [Differentiated approach to the organization of independent work of students in teaching mathematics]. Vestnik Mordovskogo universiteta, vol. 25, no 1, 30-36. (in Russian)

[3] Koryitov, I. V. (2016). Differentsiatsiya i individualnyiy podhod v obuchenii vyisshey matematike studentov tehnicheskogo vuza [Differentiation and individual approach in teaching higher mathematics to students of a technical university]. Vestnik TGPU, vol. 4(169), 33-41. (in Russian)

[4] Bukharkina, M.Yu. (2003). Tehnologiya raznourovnego obucheniya [Technology of different levels of training]. Inostrannyiy yazyik $v$ shkole, vol. 3, 48-53. (in Russian)

[5] Beloshitskiy, A. V. (2004). Opyit differentsirovannogo obucheniya v tehnicheskom vuze [Experience of differentiated education in a technical university]. Pedagogika, vol. 7, 51-54. (in Russian) 
[6] Glushkova, L. M. (2007). Realizatsiya individualnogo podhoda pri raznourovnevom problemno-modulnom obuchenii matematike $v$ tehnicheskih vuzah [Realization of the individual approach at a different level of problem-module training for mathematics in technical universities]. Vestnik Bashkirskogo universiteta, vol. 12, no 4, 211-215. (in Russian)

[7] Sharov, S. V. (2011). Vykorystannia dyferentsiiovanykh navchalnykh zavdan pid chas samostiinoi roboty studentiv [Use of differentiated educational tasks during independent work of students]. Problemy fizychnoho vykhovannia i sportu, vol. 3, 151153. (in Russian)

[8] Ilinskaya, L. N. (2013). Ob organizatsii samostoyatelnoy rabotyi studentov pedagogicheskih vuzov po kursu «matematicheskiy analiz» $v$ usloviyah urovnevoy differentsiatsii obucheniya [On the organization of independent work of students of pedagogical universities at the rate of "mathematical analysis" in the context of the level differentiation of training]. Nauka $i$ shkola, vol. 2, 95-98. (in Russian)

[9] Kostina, E. A. (2007). Postroenie differentsirovannogo obucheniya vyisshey matematike $v$ tehnicheskom vuze $s$ uchetom individualnogo profilya matematicheskih sposobnostey studenta [The construction of a differentiated instruction in higher mathematics in a technical university, taking into account the individual profile of the student's mathematical abilities]. Omskiy nauchnyiy vestnik, vol. 3 (60), 118-122. (in Russian)

[10] Mukhina, O. V. (2009). Pro dyferentsiiovane navchannia dystsyplini «Nrysna heometriia i inzhenerna hrafika» [On differentiated teaching of discipline "Descriptive geometry and engineering graphics"]. Naukovyi visnyk NLTU Ukrainy, vol. 19.11, 320-325. (in Ukrainian)

[11] Pavlutskaya, N. M. (2014). Raznourovnevyie laboratornyie rabotyi kak sredstvo formirovaniya obschekulturnyih kompetentsiy pri obuchenii fizike bakalavrov tehnicheskih napravleniy podgotovki [Various-level laboratory works as a means of forming general cultural competencies in teaching physics to bachelors of technical training areas]. Uchenyie zapiski. Teoriya $i$ metodika obucheniya fizike, vol. 6 (59), 135-138. (in Russian)

[12] Kitaevskaya, T. Yu. (2008). Sistema form organizatsii differentsirovannogo obucheniya informatike v vuze [The system of forms of organization of differentiated instruction in computer science in the university]. Vestnik TGU, vol. 13, no 1, 91-93. (in Russian)

[13] Vayndorf-Syisoeva, M. E. (2014) Pedagogika : uchebnoe posobie dlya SPO i prikladnogo bakalavriata. [Pedagogy: a textbook for secondary vocational education and applied bachelor's degree.]. Moscow: Izdatelstvo Yurayt. (in Russian)

[14] Ministerstvo osvity i nauky Ukrainy (2010) «Pro metodychni rekomendatsii shchodo zaprovadzhennia Yevropeiskoi kredytnotransfernoi systemy ta yii kliuchovykh dokumentiv u vyshchykh navchalnykh zakladakh» ["On Methodical Recommendations for the Implementation of the European Credit Transfer System and its Key Documents in Higher Educational Institutions"]. Available at: (https://ru.osvita.ua/legislation/Vishya_osvita/6810/) (accessed 16.09.2018). (in Ukrainian)

[15] Bykov, V. Yu. (2008). Tekhnolohiia stvorennia dystantsiinoho kursu: Navchalnyi posibnyk [Technology for creating a distance course: Tutorial]. Kyiv: Milenium. (in Ukrainian)

[16] Bukreeva, O. S. (2017). Ispolzovanie metoda proektov i delovyih igr v prepodavanii distsiplin v sfere otsenki sootvetstviya [Using the method of projects and business games in teaching disciplines in the sphere of conformity assessment]. Pedahohika bezpeky, vol. 2, 83-91. (in Russian)

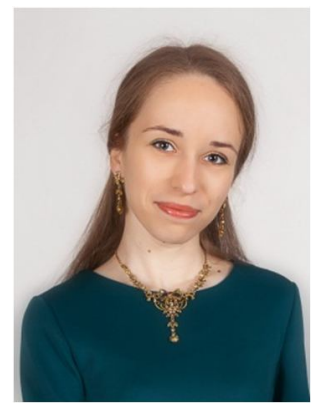

\section{Букрєєва Ольга Сергіївна,}

кандидат технічних наук, асистент кафедри метрології та безпеки життєдіяльності,

Харківський національний автомобільно-дорожній університет,

вул. Ярослава Мудрого, 25, Харків, Україна, 61002.

Тел. +38(095)359-48-67. E-mail: olga_bukreeva@ukr.net

\section{Bukrieieva Olha Serhiivna,}

Cand.Sc. (Eng.), Assistant of Metrology and Safety of Human Vital Activities Department,

Kharkiv National Automobile and Highway University,

vul. Yaroslava Mudroho, 25, Kharkiv, Ukraine, 61002.

Phone: +38(095)359-48-67. E-mail: olga_bukreeva@ukr.net

ORCID: https://orcid.org/0000-0002-3214-5269

Citation (APA):

Bukrieieva, O. (2018). Creation of the system of differential training to disciplines in the sphere of technical regulation. Engineering and Educational Technologies, 6 (3), 26-34. doi: https://doi.org/10.30929/2307-9770.2018.06.03.03 (in Russian)

\section{Цитування (ДСТУ 8302:2015):}

Букреева О. С. Создание системы разноуровневого обучения дисциплинам в сфере технического регулирования / Інженерні та освітні технології. 2018. Т. 6. № 3. С. 26-34. doi: https://doi.org/10.30929/2307-9770.2018.06.03.03

Обсяг статті: 9 сторінок, 1,034 умовних друк. аркушів. 